\title{
The Mediating Effect of Teacher Efficacy on the Relationship between Childcare Teacher's Interpersonal Stress and Turnover Intention
}

\author{
Jiyoung Lee* \\ College of Arts and Social Sciences, Tarlac State University, Tarlac, Philippines
}

*Corresponding author: Jiyoung Lee, College of Arts and Social Sciences, Tarlac State University, Tarlac, Romulo Blvd. San Vicente,

Tarlac city, Tarlac, Philippine

\begin{abstract}
ARTICLE INFO
Received: 萬 August 17, 2020

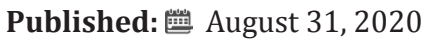

Citation: Jiyoung Lee. The Mediating Effect of Teacher Efficacy on the Relationship between Childcare Teacher's Interpersonal Stress and Turnover Intention. Biomed J Sci \& Tech Res 29(5)-2020. BJSTR. MS.ID.004872.
\end{abstract}

Keywords: Interpersonal Stress;Turnover Intention;Teacher Efficacy;Childcare Teacher

\section{ABSTRACT}

Introduction: Childcare teacher turnover is a factor that lowers the quality of childcare as it impedes the stability and continuity of childcare services. Therefore, it is crucial to find a way to decrease childcare teachers' turnover by examining the teachers' turnover intention. Against this backdrop, the purpose of this study is to analyze the effect of interpersonal stress and teacher efficacy as predictors of childcare teachers' turnover intention.

Research Method: This study used the quantitative research design with questionnaires as the principal method for gathering data. The subjects of this study were 159 childcare teachers working in childcare centers in Seoul and Gyeonggi-do, South Korea. Baik's (2007) interpersonal stress instrument, Kang's (2019) turnover intention instrument, and Hyun's (2003) teacher efficacy instrument were used as measurement tools. The collected data were analyzed using SPSS23.0. Specific analytical methods employed include descriptive statistics, correlation analysis, hierarchical regression analysis, and model 4 of PROCESS MACRO.

Findings: The findings of this study are twofold. First, the sub-factors of interpersonal stress, particularly the relationship with the director and the relationship with parents, had a significant positive effect on turnover intention, while the teacher efficacy of childcare teachers had a significant negative effect on turnover intention. Second, teacher efficacy had a mediating effect on the relationship between childcare teachers' interpersonal stress and turnover intention.

Conclusion: Childcare teacher interpersonal stress and teaching efficacy are predictors of turnover intention. Moreover, teacher efficacy acts as a mediator between childcare teachers' interpersonal stress and teacher efficacy. Therefore, in order to lower childcare teacher turnover intention, a counseling intervention meant to address childcare teacher interpersonal stress is necessary. It is also vital to develop a teacher education program that would further boost teacher efficacy.

\section{Introduction}

Childcare centers nurture infants and toddlers in a safe environment. In addition, these centers provide educational services that promote holistic development, such as cognitive, social, and emotional development of children [1]. Previous studies assert that the role of childcare teachers, the professionals who are responsible for childcare and education in childcare centers, is the most important factor in determining the quality of childcare [2-4].Considering the importance of maintaining a stable role for childcare teachers, it can be inferred that the turnover of childcare teachers is a factor that lowers the quality of childcare by impeding the stability and continuity of childcare services. This has been previously examined in a number of studies $[5,6]$. A high rate of 
turnover in childcare teachers has three significant implications. First, it makes it difficult to establish a stable and lasting relationship between childcare teachers and infants $[7,8]$, which can thereby negatively affect the development of young children. Second, it can render building parental trust in daycare centers difficult [9]. Third, it can negatively affect teachers who are still employed in the institution, such as when workloads are increased, and training of new teachers is needed [10].

Some studies related to childcare teacher turnover intention have focused on emotional stress as a major factor that causes childcare teachers to consider resigning. In particular, interpersonal relationships involving childcare teachers in childcare centers were posited as a principal source of emotional stress. These studies underscore the need to pay attention to the childcare teachers' relationship with the director, their fellow teachers, and the children's parents [11-13].Childcare teachers perform tasks under the purview of existing relationships. For one, childcare teachers assume the roles of an educator and caregiver for infants and toddlers who are learning their primary language and early communication skills. At the same time, childcare teachers are to establish a smooth relationship with the director and their fellow teachers, given that they are a part of the childcare center. More importantly, childcare teachers have to foster a collaborative relationship with the parents of the children to promote successful child development [14].Given the multitude of responsibilities falling on the shoulders of childcare teachers, interpersonal stress is expected. Interpersonal stress is defined as negative experiences caused by various types of conflict and misunderstandings that occur when a member interacts with other members to perform a given task [15-17].

It acts as a factor that causes work deterioration or emotional exhaustion. As a result, it can be a major cause for members of an organization to decide to leave the organization [18-20]. Compared with other organizations, childcare centers have a relatively simple and small organizational structure. Therefore, interpersonal relationships are close. Studies reported that stress from interpersonal relationships experienced by childcare teachers within the organization directly affects their decision to leave the institution $[12,21]$.Along with interpersonal relationships, teacher efficacy can also be considered as a variable related to the childcare teacher's turnover intention. Teacher efficacy refers to the degree by which teachers believe that they can influence the behavior of young children and their overall ability to teach [22]. Teachers with high teacher efficacy are encouraged to overcome job stress or psychological exhaustion through confidence in their abilities as teachers [23]. According to a study by Lopez (2018), teachers with high teacher efficacy showed low turnover intentions [24]. Hence, it can be argued that teacher efficacy will play a mediating role in the relationship between interpersonal stress and turnover intention.
To clarify the relationship between interpersonal stress experienced by childcare teachers and turnover intention, scholars have conducted phenomenological studies on the difficulties of human relationships experienced during childcare [25,26]. However, it is difficult to find a systematic study on how stress from various human relationships experienced by childcare teachers affect each turnover intention [27]. In line with this, this study aims to analyze the mediating effect of teacher efficacy in the relationship between interpersonal stress and turnover intention of childcare teachers.

The research questions raised in this study are as follows:

- $\quad$ First, do interpersonal stress and teacher efficacy have a significant effect on turnover intention?

- $\quad$ Second, does teacher efficacy have a mediating effect in the relationship between interpersonal stress and turnover intention?

\section{Research Method}

\section{Sampling}

The subjects of this study were 159 childcare teachers working at childcare centers in Seoul and Gyeonggi-do, South Korea.

\section{Research Tool}

The researcher primarily measured the variables in this study using a 5-point Likert scale along with various research tools. To measure interpersonal stress, Baik's (2007) measurement tool was used [28]. It consists of a total of 15 questions. Subfactors include the relationship with the director (5 items), the peer teachers ( 5 items), and the parents (5 items). Kang's (2019) measurement tool was employed to measure the turnover intention, with 6 items in the questionnaire formulated for this variable [29]. To measure teacher efficacy, the study used the measurement tool of Hyun (2003). Following Hyun's tool, a total of 13 items in the questionnaire were added [30].

\section{Analysis Method}

The collected data were treated using descriptive statistics, correlation analysis, and hierarchical regression analysis using SPSS 23.0. Mediating effect verification (model 4) and boots strapping were performed through the PROCESS MACRO 3.4 of Hayes (2013) [31]. In addition, the Sobel test was conducted to verify the statistical significance of the mediating effect.

\section{Findings}

The demographic characteristics of the subjects are shown in (Table 1). As for gender, $99.4 \%$ were females. For the age, $40.3 \%$ of them were in their $30 \mathrm{~s} .45 .3 \%$ of the subjects were college graduates of education-related majors, while only $29.6 \%$ of the subjects have $5-10 y$ rs of teaching experience. Regarding the type of childcare 
center, $60.4 \%$ are private childcare centers.(Table 2)presents the descriptive statistics of the variables. The average of interpersonal stress was 2.32 ( $\mathrm{SD}=.59$ ), and the mean of turnover intention was $3.01(\mathrm{SD}=.76)$. The average of teacher efficacy was 3.68 (SD = .63). Skewness and kurtosis did not appear to exceed 2, and normality was secured [32]. The correlation of each variable is shown in (Table 3). Interpersonal stress showed a negative correlation with turnover intention $(\mathrm{r}=.48, \mathrm{p}<.001)$ and positive correlation with teacher efficacy $(r=-.39, \mathrm{p}<.001)$. Data show that there is a negative correlation between teacher efficacy and turnover intention $(r=-.34$, $\mathrm{p}<.001)$.The results of examining the effects of interpersonal stress and teacher efficacy on turnover intention are presented in (Table 4). In Step 1, the relationship with the director $(\beta=.33, p<.001)$ and the relationship with the peer teacher $(\beta=.19, p<.05)$, which are subfactors of interpersonal stress, were statically significant vis-àvis turnover intention.

Table 1: Demographic characteristics of the study participants.

\begin{tabular}{|c|c|c|}
\hline $\begin{array}{l}\text { Demographic } \\
\text { characteristic }\end{array}$ & Descriptive Statistics & Frequency (\%) \\
\hline \multirow{2}{*}{ Gender } & Male & $1(0.6)$ \\
\hline & Female & 158(99.4) \\
\hline \multirow{4}{*}{ Age } & $20 \mathrm{~s}$ & $33(20.8)$ \\
\hline & $30 \mathrm{~s}$ & $64(40.3)$ \\
\hline & $40 \mathrm{~s}$ & $54(34.0)$ \\
\hline & $50 \mathrm{~s}$ & $8(5.0)$ \\
\hline \multirow{4}{*}{ Education Background } & High school & $14(8.8)$ \\
\hline & College (2 3yrs) & $72(45.3)$ \\
\hline & University (4yrs) & $57(35.8)$ \\
\hline & Graduate school & $16(10.1)$ \\
\hline \multirow{5}{*}{ Teaching career } & under 1yr & $10(6.3)$ \\
\hline & $1 \sim 3 y r s$ & $35(22.0)$ \\
\hline & $3 \sim 5 \mathrm{yrs}$ & $35(22.0)$ \\
\hline & 5 10yrs & $47(29.6)$ \\
\hline & over 10 yrs & $32(20.1)$ \\
\hline \multirow{4}{*}{ Type of childcare center } & Public & $15(9.4)$ \\
\hline & $\begin{array}{l}\text { Corporation or } \\
\text { workplace }\end{array}$ & $9(5.7)$ \\
\hline & Private & $96(60.4)$ \\
\hline & Home & $39(24.5)$ \\
\hline Total & & $159(100)$ \\
\hline
\end{tabular}

Table 2: Descriptive statistics of variables.

\begin{tabular}{|c|c|c|c|c|}
\hline & $\mathbf{M}$ & SD & Skewness & Kurtosis \\
\hline Interpersonal Stress & 2.32 & .59 & -.24 & .41 \\
\hline $\begin{array}{c}\text { the relationship with the } \\
\text { director }\end{array}$ & 2.48 & .81 & -.03 & .03 \\
\hline $\begin{array}{c}\text { the relationship with the } \\
\text { peer teachers }\end{array}$ & 2.10 & .71 & .27 & -.20 \\
\hline the relationship with parents & 2.40 & .76 & .40 & .41 \\
\hline
\end{tabular}

\begin{tabular}{|c|c|c|c|c|}
\hline turnover intention & 3.01 & .76 & -.20 & .16 \\
\hline Teacher efficacy & 3.68 & .63 & -.21 & .44 \\
\hline
\end{tabular}

Table 3: Correlation of variables.

\begin{tabular}{|c|c|c|c|c|c|c|}
\hline & 1 & 2 & 3 & 4 & 5 & 6 \\
\hline $\begin{array}{l}\text { 1. Interpersonal } \\
\text { Stress }\end{array}$ & 1 & & & & & \\
\hline $\begin{array}{l}\text { 2. the relationship } \\
\text { with the director }\end{array}$ & $.77^{* * *}$ & 1 & & & & \\
\hline $\begin{array}{l}\text { 3. the relationship } \\
\text { with the peer } \\
\text { teachers }\end{array}$ & $.79^{* * *}$ & $.46^{* * *}$ & 1 & & & \\
\hline $\begin{array}{l}\text { 4. the relationship } \\
\text { with parents }\end{array}$ & $.72^{* * *}$ & $.26^{* *}$ & $.39 * * *$ & 1 & & \\
\hline 5. turnover intention & $.48^{* * *}$ & $.43^{* * *}$ & $.35^{* * *}$ & $.32^{* * *}$ & 1 & \\
\hline 6. Teacher efficacy & $-.39 * * *$ & $-.23^{* *}$ & $-.33^{* * *}$ & $-.33^{* * *}$ & $-.34^{* * *}$ & 1 \\
\hline
\end{tabular}

Note: ${ }^{* *} \mathrm{p}<.01,{ }^{* * *} \mathrm{p}<.001$

Table 4: Hierarchical regression on turnover intention of interpersonal stress and teacher efficacy.

\begin{tabular}{|c|c|c|c|c|}
\hline \multirow{2}{*}{ Variables } & \multicolumn{2}{|c|}{ Step 1 } & \multicolumn{2}{c|}{ step2 } \\
\cline { 2 - 5 } & $\boldsymbol{\beta}$ & $\mathbf{t}$ & $\boldsymbol{\beta}$ & $\mathbf{t}$ \\
\hline $\begin{array}{c}\text { The relationship with the } \\
\text { director }\end{array}$ & .33 & $4.07^{* * *}$ & .32 & $3.97^{* * *}$ \\
\hline $\begin{array}{c}\text { The relationship with the } \\
\text { peer teachers }\end{array}$ & .12 & 1.35 & .07 & .86 \\
\hline $\begin{array}{c}\text { The relationship with parents } \\
\text { Teacher efficacy }\end{array}$ & .19 & $2.36^{*}$ & .14 & 1.78 \\
\hline $\mathrm{F}$ & $15.50^{* * *}$ & $13.63^{* * *}$ & $-2.52^{*}$ \\
\hline $\mathrm{R}^{2}$ & .242 & \multicolumn{2}{|c|}{.273} \\
\hline $\mathrm{R}^{2}$ & \multicolumn{2}{|c|}{.242} & \multicolumn{2}{|c|}{.032} \\
\hline
\end{tabular}

Note: ${ }^{*} \mathrm{p}<.05,{ }^{* * *} \mathrm{p}<.001$

In addition, the explanatory power for the turnover intention of interpersonal stress was $24.2 \%$. In Step 2, teacher efficacy was found to have a significant negative effect on turnover intention $(\beta=-.19, p<.05)$. Teacher efficacy's explanatory power for turnover intention was $3.2 \%$.(Table 5)shows the results of verifying the mediating effect of teacher efficacy. The influence of interpersonal stress on teacher efficacy was $14.9 \%$, and it was found to have a significant negative effect $(B=-.42, p<.001)$. The influence of interpersonal stress and teacher efficacy on turnover intention was $25.8 \%$. Interpersonal stress was found to have a significant positive effect on turnover intention $(\mathrm{B}=.54, \mathrm{p}<.001)$, and teacher efficacy $(\mathrm{B}=-.22, \mathrm{p}<.05)$ was found to have a significant negative effect. appear. The mediating effect of interpersonal stress on turnover intention through teacher efficacy was found to be significant, and the mediating effect of teacher efficacy was verified. As a result of the Sobel test, $\mathrm{z}$ was statistically significant as 3.78 ( $\mathrm{p}<.001)$. 
Table 5: Mediating effect of teacher efficacy.

\begin{tabular}{|c|c|c|c|c|c|c|}
\hline Independent Variable & Dependent Variable & B & SE & $\mathbf{t}$ & $\mathbf{F}$ & $\mathbf{R}^{2}$ \\
\hline IS & TE & -.42 & .08 & $-5.09^{* * *}$ & $25.880^{* * *}$ & .149 \\
\hline IS & \multirow{2}{*}{$\mathrm{TI}$} & .54 & .10 & $5.34^{* * *}$ & $25.532^{* * *}$ & .258 \\
\hline $\mathrm{TE}$ & & -.22 & .09 & $-2.32^{*}$ & & \\
\hline \multirow{2}{*}{\multicolumn{2}{|c|}{ Indirect effect path }} & \multirow{2}{*}{$\mathrm{B}$} & \multirow{2}{*}{ SE } & \multicolumn{3}{|c|}{$95 \%$ confidence interval } \\
\hline & & & & \multicolumn{2}{|c|}{ LLCI } & ULCI \\
\hline \multicolumn{2}{|c|}{ IS-TE-TI } & .54 & .10 & \multicolumn{2}{|c|}{.33} & .74 \\
\hline
\end{tabular}

Note: ${ }^{*} \mathrm{p}<.05,{ }^{* * *} \mathrm{p}<.001$

IS: Interpersonal Stress, TE: Teacher Efficacy, TI: Turnover Intention.

\section{Discussion and Conclusion}

This study was conducted to analyze the mediating effect of teacher efficacy in the relationship between childcare teacher's interpersonal stress and turnover intention. The discussion based on the results of this study is as follows. First, results show that the childcare teacher's interpersonal relationship stress and teacher efficacy have a significant effect on turnover intention. In particular, among the subfactors of interpersonal stress, the relationship with the director and relationship with parents have a significant positive effect. These results are similar to the results of a study that argued that interpersonal conflict had a significant effect on employees' turnover intention [33]. In addition, it can be said that the results are similar to the results of Kwon \& Kwon (2017) that the early childhood teachers' teacher efficacy has a significant influence on the intention to turnover [34]. Therefore, the higher the childcare teachers' stress from their interpersonal relationship with the director and parents, the higher the turnover intention. In line with this, it is necessary to mediate the interpersonal stress of childcare teachers to lower the turnover intention of childcare teachers.Teacher efficacy of childcare teachers was found to have a significant positive effect on turnover intention. This result is in the same light with previous findings that when the teacher experiences stress at the interpersonal level, the teacher's ability is impaired, thereby creating a negative effect on the teacher [35].

Considering this, to lower the turnover intention of childcare teachers, it is necessary to develop an educational program that would improve teacher efficacy.Second, results confirm that teacher efficacy has a mediating effect in the relationship between childcare teacher's interpersonal stress and turnover intention. This can be said to be similar to the results of the study by Yoo\& Kwon (2017) that the job stress of childcare teachers has a significant effect on turnover intention through teacher efficacy and burnout [36]. In other words, interpersonal stress acts as a factor that lowers teacher efficacy, which in turn affects turnover intention. Therefore, counseling intervention is advisable to alleviate the interpersonal stress experienced by childcare teachers at work.Since this study primarily involves teachers working in daycare centers in Seoul and Gyeonggi-do in South Korea, subsequent studies related to this study's focus may do well in broadening the research subject. Moreover, follow-up studies can opt to use alternative data gathering techniques such as in-depth interviews, instead of survey questionnaires, to provide a more in-depth examination of the relationship between interpersonal stress, teacher efficacy, and turnover intention among childcare teachers.

\section{References}

1. Jang SO (2015) An Analysis of Research Trends in Physical Environment of Early Childhood Education Institutions. Early Childhood Education Research \& Review 19(5): 143-170.

2. Kim MS, Shin YS, Chae EW (2016) Effects of nursing teacher's efficacy and professionalism on childhood curriculum performance. Korean Journal of Child Studies 37(2): 43-56.

3. Jeon KK (2018) The effect of teacher's temperament and teacher-toddler interaction and attachment stability on infant cognitive development. Doctoral dissertation, Kukje Theological Seminary.

4. Myers JP (2006) Rethinking the social studies curriculum in the context of glottalization: Education for global citizenship in the US. Theory and Research in Social Education 34(3): 370-394.

5. Cassidy DJ, Lower JK, Kintner Duffy VL, Hegde AV, Shim J (2011) The dayto-day reality of teacher turnover in preschool classrooms: An analysis of classroom context and teacher director and parent perspectives. Journal of Research in Childhood Education 25(1): 1-23.

6. Hale Jinks C, Knopf H, Kemple K (2006) Tackling teacher turnover in childcare: understanding causes and consequences, identifying solutions. Childhood Education 82(4): 219.

7. Beak YS (2014) A study on moderating effects of personally environmentally protective factors in the relationship between childcare teachers' job stress and turnover intentions. Doctoral dissertation, Sookmyung Women's University.

8. Cryer D, Hurwitz S, Wolery M (2003) Continuity of Caregiver for Infants and Toddlers. ERIC: ED482881.

9. Howes C, Hamilton CE (1992) Children's relationship with childcare teacher: Stability and concordance with parental attachment. Child Development 63(2): 867-868.

10. Shin YI (2018) The Effect of Job Stress Factors on Turnover Intention in Nursery Facilities: Focused on the Mediating Effect of Teacher's Burnout and Emotional Labor. Journal of Future Social Work Research 9(1): 3564.

11. Kim GO (2016) The effects of emotional intelligence and childcare teacher's job stress on turnover intentions. The Journal of Creative Personality with MeFOT 5(1): 5-22.

12. Han EK (2018) The influences of the empowerments and the job stresses of the nursing teachers on the intention to change the job. master thesis, Incheon National University. 
13. Kelly AL, Berthelsen DC (1995) Preschool teachers' experience of stress. Teaching and Teacher Education 11(4): 345-357.

14. Sung MY, Kim JK, Seo JH, Min MH, Kim YM (2015) Childcare Teacher Theory. Seoul, South Korea: Hakjisa.

15. Kim HR, Auh SY (2017) The Impact of Early Childhood Teachers Interpersonal Stress on Teacher Efficacy: A Focus on Mediation Effects of Happiness. Early Childhood Education Research \& Review 21(6): 77103.

16. Kato TQ (2013) Assessing coping with interpersonal stress: Development and validation of the interpersonal stress coping scale in Japan. International Perspectives in Psychology: Research practice Consultation 2(2): 100-115.

17. Thanh LV (2016) Relationship at work as a cause of occupational stress: The case of academic women in Vietnam. International Journal of Mental Health Systems 42(10): 1-15

18. Kim SY (2015) The effects of job stress and interpersonal skills on the psychological burnout among directors of early childhood education center. Master thesis. Graduate School of Education, Jeonbuk National Univeristy Jeonju, Korea.

19. Chang CH, Rosen CC, Levy PE (2009) The relationship between perceptions of organizational politics and employee attitudes strain and behavior: A meta-analytic examination. Academy of Management Journal 52(4): 779-801.

20. Rodríguez Mantilla JM, Fernández Díaz MJ (2017) The effect of interpersonal relationships on burnout syndrome in secondary education teachers. Psicothema, 29(3): 370-377.

21. Ko GP, Sim MY (2017) The Mediation Effect of Child-care Teachers' Psychological Well-being on Job Stress and Turnover Intention. The Journal of Learner-Centered Curriculum and Instruction 17(9): 313333.

22. Lee JY (2012) The Effects of Childcare Teachers' Self-esteem and Teacher Efficacy on Job Stress. Master thesis, Korea University.

23. Wudy DT Jerusalem M (2011) Changes in teachers' self-efficacy and experiences of stress. Psychologie in Erziehung and Unterricht 58(4): 254-267.

24. Lopez V (2018) Teachers' job satisfaction and efficacy as indicators of intent-to leave teaching. Doctoral dissertation, Walden University.

\section{ISSN: 2574-1241}

DOI: $10.26717 / B J S T R .2020 .29 .004872$

Jiyoung Lee. Biomed J Sci \& Tech Res

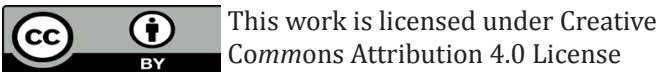

Submission Link: https://biomedres.us/submit-manuscript.php
25. Son HK (2015) The difficulty that head teacher in childcare center has in the human relation and the effort to overcome it. Master thesis, Chungang University.

26. Shin HS (2017) A study on the difficulties and solutions of childcare teachers in relation with parents. Master thesis, Chungang University.

27. Cha SJ (2019) The Effect of the Interpersonal Stress and Childcare Teacher's Perception of Professionalism on the Turnover Intention. Master thesis, Yonsei University.

28. Baik JC (2007) Possible effects of interpersonal relationship on working mindset and turnover intention. Doctoral dissertation, Uiduk University.

29. Kang GS (2019) The effects of the child-care teacher's emotional labor on turnover intention-The mediating effects of the servant leadership of the directors and the job exhaustion. Doctoral dissertation, Pyeongtaek University.

30. Hyun JH (2013) Relations between a teacher's childcare efficacy and resilience. Korea Journal of Child Care and Education 82: 147-162.

31. Hayes AF (2013) Methodology in the social sciences. Introduction to mediation, moderation, and conditional process analysis: A regressionbased approach. New York: Guilford Press.

32. Woo JP (2012) Structural equation model concept and understanding, Seoul, South Korea: Hannarae.

33. Bhayo AR, Shah N, Chachar AA (2017) The impact of interpersonal conflict and job stress on employees' turnover intention. International Research Journal of Arts and Humanities.

34. Kwon HS, Kwon SM (2017) The effects of a kindergarten teacher's empowerment, life stance and teacher efficacy on turnover intentions the mediated effects of burnout and social support. The Journal of Korea Open Association for Early Childhood Education 22(1): 379-401.

35. Prilleltensky I, Neff M, Bessell A (2016) Teacher stress: What it is, why it is important, how it can be alleviated? Psychological Science at Work in Schools and Education 55(2): 104-111.

36. Yoo HS, Kwon JH (2017) Structural Relations among Child Care Teachers' Job Stress, Teacher Efficacy, Organizational Commitment, Burn-out and Turnover Intention. Early Childhood Education Research \& Review 21(1): 113-132.

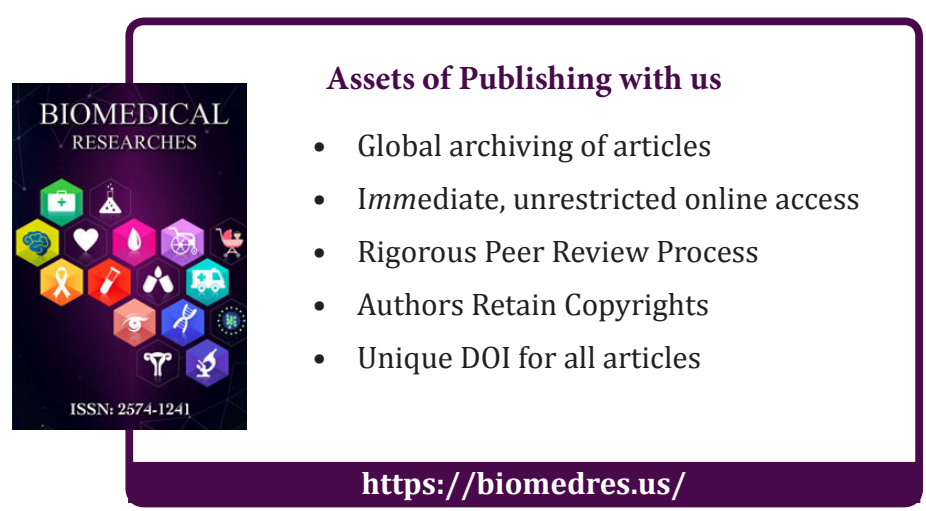

